\title{
The Meanings and Strategies of Quality Evaluation System about Innovation and Entrepreneurship in Higher Vocational Colleges
}

\author{
Jing Liu \\ Wuhan Railway Vocational College of Technology, Wuhan 430205, China \\ 376237124@qq.com
}

\begin{abstract}
The innovation and entrepreneurship education evaluation system play an important role in the process of implementing innovation and entrepreneurship education in higher vocational colleges. On the basis of studying the meanings of the evaluation system of innovation and entrepreneurship education in higher vocational colleges, this paper analyzes the problems existing in the evaluation system of innovation and entrepreneurship education in higher vocational colleges, and puts forward three strategies which focus on how to construct the innovation and entrepreneurship system.
\end{abstract}

Keywords: Higher vocational colleges; quality evaluation system of innovation and entrepreneurship education; meanings and strategies.

\section{The Context of the Problem}

In 2015, the General Office of the CPC Central Committee and the State Council issued the "Implementation Opinions on Deepening the Reform of Innovation and Entrepreneurship Education in Colleges and Universities". The National "Thirteenth Five-Year Plan" and the report of the 19th National Congress of the Communist Party of China also re-emphasized "inspiring the vitality of innovation and entrepreneurship and promoting The call for mass entrepreneurship and innovation". The series of national policies marks that the innovation and entrepreneurship education has been explored from the experimenting phase to a new era of comprehensive promotion and in-depth exploration.

Under the background of "mass entrepreneurship and innovation", the Hubei Provincial Party Committee and the provincial government attach great importance to the work of innovation and entrepreneurship education in colleges and universities. It has clearly stated that it will concentrate resources to create "the city of the university", "the city of youth" and "the city of dreams". "City of Innovation", It is deserving to look forward to the innovation and entrepreneurship education of Hubei. Compared with ordinary colleges and universities, higher vocational colleges tend to cultivate applied talents. How to improve students' ability of innovation and entrepreneurship has become an important research topic in higher vocational education. At present, higher vocational colleges generally actively carry out and explore innovative entrepreneurship education, but research on its quality evaluation system is still scarce. Constructing a scientific quality evaluation system for innovation and entrepreneurship education in Hubei higher vocational colleges will help to deepen the focus of how to improve the quality of innovation and entrepreneurship education.

\section{The Meanings of the Quality Evaluation System of Innovation and Entrepreneurship Education}

(1)The quality evaluation method of innovation and entrepreneurship education. Lee, Chang \& Lim (2005) grouped American and Korean students according to whether they participated in the innovation and entrepreneurship curriculum, and explored the impact of entrepreneurship courses on students' entrepreneurial interest, measured by experimental methods. Lorz, Mueller (2013) believes that the measurement of students' innovation and entrepreneurship afterwards will weaken the persuasiveness of the research results, because the quality of innovation and entrepreneurship education is affected by many external factors, such as time, quality of the course, and the wishes of 
the person. Scholar Colette Henry (2016) believes that the six-step evaluation method proposed by Storey so far is very suitable for evaluating entrepreneurship education. When evaluating the effectiveness of entrepreneurship education, the framework pays attention to the use of paired experiments with control groups, and pays attention to ensuring the scientificity and effectiveness of experimental comparisons. China $\mathrm{Ge} \mathrm{Li} \mathrm{(2014)} \mathrm{takes} \mathrm{the} \mathrm{students} \mathrm{of} 9$ key universities in China as the experimental objects, and comprehensively studies the three modes of CIPP in college entrepreneurship education through survey analysis and data analysis. They are a guiding model that emphasizes the results of innovation and entrepreneurship, a guiding model that emphasizes the innovation and entrepreneurial environment, and a guiding model that emphasizes the process of innovation and entrepreneurship education.

(2) Index system of Innovation and Entrepreneurship quality evaluation. At present, scholars' research on the index system of innovation and entrepreneurship education is based on the following two directions: entrepreneurial results or entrepreneurial ability. Block and Stumpf summarized the corresponding evaluation indicators according to different measurement periods in 1992. In the short term, it mainly measures the basic situation of students' learning at school, such as the specific rate in the class rate and entrepreneurial activities. The long-term effect is mainly to track the entrepreneurial situation of students after graduating from school, and to measure the performance of students' work and the benefits brought by entrepreneurial activities to the society. Kuratko Professor Krakow (2014) pointed out that the entrepreneurship teaching curriculum system, entrepreneurship training platform and entrepreneurship education conditions form the existing entrepreneurial education environment. Colete (2015) constructed an innovation and entrepreneurship evaluation system from seven aspects: organizational capacity training, entrepreneurship education curriculum, and entrepreneurial environment. Based on the CIPP model, Ge Li (2014) explored the construction of the quality evaluation system for innovation and entrepreneurship education from the aspects of basic conditioning construction, tje resource level, and the quality track of post-graduate students.

(3)Problems in the quality evaluation of innovation and entrepreneurship education. Tan Jinxi (2017) believes that the current colleges and universities generally ignore the long-term effects, and pay attention to the results of innovation and entrepreneurship education in the short term.what's more ,the school's exploration of the influencing factors of education evaluation is not deep enough and comprehensive, and no third-party evaluation is introduced. Wang Xingli (2018) proposed that there are four problems. First, the innovation and entrepreneurship education is generally carried out in Chinese universities, but the systematic and scientific evaluation system has not yet appeared. Second, universities generally pay attention to short-term benefits, neglecting to cultivate students' ability. The third is that there is no comprehensive evaluation method. At present, schools mainly use the student evaluation. People have defined the meaning of innovation and entrepreneurship education from different angles, but so far there is no uniform definition. By reading a large amount of relevant literature, this paper believes that innovation and entrepreneurship education is part of higher education, aiming at meet the needs of the comprehensive development of people and the society. IT emphasizes on the spirit of innovation, creative thinking, the cultivation of comprehensive quality and practical ability. It will enable students to independently discover problems, solve problems, and present their own new ideas. Finally, our students will become talents with solid professional knowledge, innovative spirit, and courage to practice. By reading a large number of related literatures, this paper considers that the following six elements constitute of evaluation system of innovation and entrepreneurship education: value orientation, evaluation objectives, evaluation content, evaluation indicators, evaluation methods, and evaluation continuity.

\section{The Strategy Research on the Quality Evaluation System of Innovation and Entrepreneurship Education}

1. Improve the effectiveness of research methods for the evaluation system of innovation and entrepreneurship education. Up to now, all colleges and universities in China have carried out innovation and entrepreneurship education, but the construction of their education evaluation system 
is still in the exploratory period. The quality evaluation system of innovation and entrepreneurship education in different regions and different levels of universities is different, to define the science of innovation and entrepreneurship education. The evaluation of indicator systems and practice exchanges has brought difficulties. In-depth discussion on the quality evaluation system of innovation and entrepreneurship education can be carried out according to the steps of "interpreting connotation, theoretical reference, surveying the status quo, reflecting problems, and constructing strategies". Taking the spirit of the national innovation and entrepreneurship education policy document as the starting point, starting from the micro level, the analysis framework combining system analysis and key case perspective is adopted. Based on the internal logic of the six dimensions of the evaluation system of innovation and entrepreneurship education, combined with the survey results of typical higher vocational colleges, using Delphi method, analytic hierarchy process and fuzzy comprehensive evaluation method to construct the quality evaluation of innovation and entrepreneurship education in Hubei higher vocational colleges system.

2. Strengthen the practical research on the evaluation of innovation and entrepreneurship education in higher vocational colleges. In the evaluation system of innovation and entrepreneurship education in higher vocational colleges, it is necessary to solve the following problems: the existing research usually uses the innovation and entrepreneurship education of undergraduate colleges as the evaluation subject, and there are few related researches for higher vocational colleges. The research is fragmented and lacks systematicity. There are generally no theoretical foundations or accumulations of previous explorations in China. Many studies have directly derived the evaluation system of innovation and entrepreneurship education based on the research on a small number of educational objects that they have contacted, lacking universality and objectivity. Research lacks exploration of the effects of practice. At present, most of the existing researches are the study of academic rationality, but the innovation and entrepreneurship education is actually a very practical education. At present, there is very little discussion on the actual use effect of the evaluation model. Strengthen the multi-dimensional and integrated construction of the evaluation system of entrepreneurial innovation and entrepreneurship, and study the differences and connections between different types of innovation and entrepreneurship education activities. Improve the scientific, practical and flexible evaluation system of innovation and entrepreneurship education, so that it can adapt to efficient and different entrepreneurial environments and entrepreneurial projects. The quality evaluation system of innovation and entrepreneurship education must be practical. It is characterized by creating a model based on big data, controlling the quality of innovation and entrepreneurship education, embodying its practicality, better integrating into social construction, and contributing to innovation and new entrepreneurship.

3. Construct a "four-in-one" innovation and entrepreneurship education evaluation system for higher vocational colleges. Through the analysis of the factors influencing the evaluation of innovation and entrepreneurship education in higher vocational colleges, this paper believes that the innovation and entrepreneurship education evaluation system can be constructed in four factors: government, society, higher vocational colleges and students. At the government level, it is necessary to strengthen the concept guidance and policy support for the evaluation of innovation and entrepreneurship education in higher vocational colleges. At the social level, enterprises need to strengthen exchanges with higher vocational colleges, and improve the conversion rate and recognition of innovation results. At the school level, the teachers should change their opinion towards the awareness of innovation and entrepreneurship, the evaluation system of speciality and the evaluation system of curriculum. At the student level, students need to inspire their awareness of innovation and entrepreneurship, and become keen on setting up innovative and entrepreneurial teams.

\section{Acknowledgments}

Jing Liu (1985-), female, Xiantao native of Hubei Province, lecturer from Wuhan railway vocational college of technology, research direction is higher vocational education management. 


\section{References}

[1]. Yang Haihua. Reflections on the Construction of the Evaluation System of Secondary Vocational Education[J]. Journal of Jiangsu Education, 2016 (12): 21-24.

[2]. Liu Leilei. Research on the Construction and Reform Path of Innovation and Entrepreneurship Education Evaluation System in Colleges and Universities_-Based on the Investigation of 64 Universities in Zhejiang Province[J]. Education and Teaching Forum, 2017(31).

[3]. Li Xuhui, Research on the evaluation system of innovation and entrepreneurship education in colleges and universities__analysis based on group G1 method[J]. Journal of Educational Development Research, 2016, (21). 